\title{
Capsule Commentary on Saloner et al., Price Transparency in Primary Care: Can Patients Learn About Costs When Scheduling an Appointment?
}

\author{
Cameron M. Kaplan, PhD \\ Department of Preventive Medicine, University of Tennessee Health Science Center, Memphis, TN, USA.
}

J Gen Intern Med 32(7):801

DOI: $10.1007 / \mathrm{s} 11606-017-4055-5$

() Society of General Internal Medicine 2017

$\mathrm{O}$ ne of the promises of the recent push for high-deductible, consumer-driven health plans is that they can reduce health care costs and improve quality, because patients can comparison-shop. However, this promise can be fulfilled only if patients have access to price information and use it to make decisions. Primary care is an important area in which to examine price transparency, because it is easy for patients to plan ahead for and thus to perform cost comparisons. Additionally, primary care is widely used and is often subject to patients' deductibles. At the same time, new requirements for insurers to cover certain preventive services without a co-pay adds to the confusion about how much typical primary care visits will cost.

This study by Saloner et al. ${ }^{1}$ used an innovative methodology in which simulated patient callers attempted to obtain price information for the cost of typical primary care visits. These simulated callers included individuals with employer-sponsored insurance, ACA marketplace plans, or no insurance. Although the uninsured were able to get price information in $89.2 \%$ of all calls, those with employer-sponsored insurance and marketplace plans were successful in obtaining price information at much lower rates ( $61.8 \%$ and $47.3 \%$, respectively).

The nature of the United States health care system, where providers negotiate prices with many different payers, means that it may be difficult for providers to provide accurate price information for insured patients, and recent health care reform has made this problem more acute by adding new types of insurance and new benefits. On the other hand, online price transparency tools offered by insurers are underutilized and do not seem to lead to reduced costs. ${ }^{2,3}$ A recent survey found that consumers were more likely to attempt to get price information directly from their physician or office staff than from their insurance provider. ${ }^{4}$ Thus, in order to improve price transparency, and to deliver on the promise of better, cheaper health care through consumer-driven health plans, we need new and innovative ways of delivering accurate price information to patients from sources they trust and can easily access.

Corresponding Author: Cameron M. Kaplan, PhD; Department of Preventive MedicineUniversity of Tennessee Health Science Center, Memphis, TN, USA (e-mail: ckaplan@uthsc.edu).

\section{Compliance with Ethical Standards:}

Conflict of Interest: The author has no conflicts of interest with this article.

\section{REFERENCES}

1. Saloner B, Cope LC, Hempstead K, Rhodes KV, Polsky D, Kenney GM. Price transparency in primary care: can patients learn about costs when scheduling an appointment? J Gen Intern Med. 2017. doi:10.1007/ s11606-017-4003-4.

2. Sinaiko AD, Rosenthal MB. Examining a health care price transparency tool: who uses it, and how they shop for care. Health Aff. 2016;35(4):662-670.

3. Desai S, Hatfield LA, Hicks AL, Chernew ME, Mehrotra A. Association between availability of a price transparency tool and outpatient spending. JAMA. 2016;315(17):1874-1881.

4. Schleifer D, Hagelskamp C, Rinehart C. How much will it cost? How Americans use prices in health care. New York: Public Agenda. 2015. Available at: https://www.publicagenda.org/pages/how-much-will-it-cost. Accessed 20 March 2017 